\title{
LEVANTAMENTO PEDOLÓGICO E SISTEMA DE INFORMAÇÕES GEOGRÁFICAS NAAVALIAÇ̃̃O DO USO DAS TERRAS EM SUB-BACIA HIDROGRÁFICA DE MINAS GERAIS ${ }^{1}$
}

\author{
Pedologic survey and geographic information system for evaluation of land use \\ within a small watershed, Minas Gerais State, Brazil
}

\author{
Michele Duarte de Menezes ${ }^{2}$, Nilton Curi³ João José Marques ${ }^{3}$, \\ Carlos Rogério de Mello ${ }^{4}$, Alexandre Romeiro de Araújo ${ }^{5}$
}

\begin{abstract}
RESUMO
A aptidão agrícola das terras consiste em uma classificação técnica que identifica o potencial agrícola de utilização das mesmas, considerando as limitações do solo em níveis de manejo diferenciados a partir das informações geradas em um levantamento pedológico. O cruzamento dos dados de aptidão agrícola e uso atual das terras em ambiente SIG (Sistema de Informações Geográficas) consiste numa ferramenta adequada de planejamento, pois permite determinar a inadequação entre uso e aptidão agrícola, dando bases sustentáveis à exploração. Neste estudo, foram realizadas a avaliação da aptidão agrícola das terras e seu uso atual com auxílio de imagens de satélite e observações de campo, e a identificação de Áreas de Preservação Permanente (APPs) em uma sub-bacia hidrográfica da Bacia do Alto Rio Grande, MG. Com base no levantamento de solos, a utilização do sensoriamento remoto, por meio de imagens de satélites, aliado ao ambiente SIG, constituem-se em ferramentas adequadas para avaliação da aptidão agrícola e uso atual das terras, e permitem o monitoramento das áreas da sub-bacia hidrográfica. O levantamento pedológico forneceu uma base segura e real para que, com o auxílio de ferramentas de geoprocessamento, os mapas resultantes tivessem melhor qualidade e representassem com acurácia os diferentes ambientes naturais na paisagem da sub-bacia hidrográfica. Ocorreu o predomínio de usos da terra menos intensivos que os das classes de aptidão agrícola encontradas. As Áreas de Preservação Permanente (APPs) estão recebendo os mais diferentes usos agrícolas, caracterizando uma inadequação entre a legislação ambiental e o uso atual da terra.
\end{abstract}

Termos para indexação: Aptidão Agrícola das Terras, Áreas de Preservação Permanente, Taxa de Adequação de Uso.

\section{ABSTRACT}

The land agricultural suitability is a technical classification that identifies the agricultural potential of land use, considering the soil limitations at differential management levels from the information generated in a pedologic survey. The cross reference of data involving land agricultural suitability and land use in Geographical Information System (GIS) is an adequate tool for planning, because it allows to determine the inadequacy between land use and land agricultural suitability, giving bases to sustainable exploration. Therefore, we evaluated in this work the land agricultural suitability and the current use of the land mediated by satellite images and field observations, for the identification of permanent preservation areas (PPAs) in a small watershed from Alto Rio Grande basin - MG. Based on soil survey, the utilization of remote sensing, by means of satellite images, in association with GIS, constitutes adequate tools to evaluate the land suitability and current use, and allows monitoring areas of the small watershed. The pedologic survey supplied a secure and real basis for this purpose and with the help of geoprocessing tools, the resulting maps had better quality and represented with accuracy the different natural environments in the landscape of the hydrographic small watershed. We observed a dominance of less intensive land use in relation to the agricultural suitability classes found here. The permanent preservation areas (PPAs) are receiving a variety of agricultural uses, which characterizes an inadequacy between the environmental legislation and the current land use.

Index terms: Land agricultural suitability, Permanent Preservation Areas, Ratio of Adequate Use.

(Recebido em 14 de novembro de 2007 e aprovado em 25 de novembro de 2008)

\section{INTRODUÇÃo}

A zona fisiográfica Campos das Vertentes, na qual se insere a sub-bacia em estudo, apresenta predomínio de relevo ondulado e das classes de Latossolos (em relevo relativamente mais suavizado) e Cambissolos (relevo mais acidentado), sendo diagnosticadas como principais problemas desses últimos solos a baixa infiltração de água e a alta estimativa de perdas de solo (415 $\left.\mathrm{t} \mathrm{ha}^{-1} \mathrm{ano}^{-1}\right)$ (Giarola, 1994; Motta et al., 2001). A baixa fertilidade natural

\footnotetext{
${ }^{1}$ Parte da Dissertação de Mestrado da primeira autora, apresentado à Universidade Federal de Lavras/UFLA.

Engenheira Agrônoma, Mestre - Rua Carlos Gomes, 183 - São Bernardo do Campo/SP - CEP 097515-530 - michele duarte@ig.com.br

${ }^{3}$ Engenheiro Agrônomo, Ph.D. - Professores do Departamento de Ciência do Solo/DCS - Universidade Federal de Lavras/UFLA - Cx. P. 3037 - 37200 000 - Lavras, MG - niltcuri@dcs.ufla.br, jmarques@dcs.ufla.br

${ }^{4}$ Engenheiro Agrícola, Doutor - Professor do Departamento de Engenharia/DAE - Universidade Federal de Lavras/UFLA - Cx. P. 3037 - $37200-000$ Lavras, MG - crmello@ufla.br.

${ }^{5}$ Zootecnista, Doutor - Centro de Tecnologia Canavieira - Piracicaba/SP - Cx. P. 162 - 13400-970 - araraujo@ctc.com.br
} 
é uma restrição importante e comum a ambas as classes de solos. A atividade econômica predominante é a pecuária leiteira, sendo as terras ocupadas, em grande parte, por pastagens nativas com pouco uso de tecnologias que visem à melhoria do desempenho da vegetação natural (Curi et al., 1994; Resende \& Pereira, 1994).

O uso das terras e a falta de planejamento da produção agrícola têm comprometido a capacidade de sustentação dos sistemas naturais, submetendo-os à degradação e à perda de produtividade, com repercussão ambiental, econômica e social negativa, em âmbito local e regional. Nesse contexto, inserese a aptidão agrícola das terras, cuja avaliação tem como finalidade a indicação do potencial agrícola das terras para diferentes tipos de uso, procurando atender a uma relação custo/benefício favorável sob os pontos de vista econômico e ambiental (Ramalho Filho \& Beek, 1995). Esse método de classificação deve ser entendido não apenas como uma recomendação para uso direto pelos produtores rurais, mas como uma base para o planejamento agrícola, pois fornece opções de uso cuja escolha deve considerar, ainda, outros fatores, como o fator sócioeconômico, a legislação ambiental e o interesse do produtor.

Os mapas de aptidão agrícola das terras, quando cruzados e sobrepostos com mapas de uso atual e áreas de preservação permanente, permitem determinar áreas com inadequação de uso (Pedron et al., 2006) e o nível de utilização das terras (Gomes et al., 2007). Nesse sentido, o ambiente SIG torna-se uma ferramenta fundamental para tomadas de decisão na gestão ambiental, em razão da possibilidade de detecção da taxa de adequação entre aptidão agrícola e uso das terras, sendo um sistema realístico, semiautomático e não subjetivo (Formaggio et al., 1992). Dessa maneira, é possível planejar o uso das terras o que é importante no cenário agrícola atual, que busca maior competitividade bem como a conservação dos recursos naturais (Silva et al., 2008).

Segundo Roy \& Tomar (1999), as intervenções antrópicas no sistema natural resultam em alterações na composição e distribuição da vegetação no tempo e no espaço. O uso de SIGs é ideal para acompanhar a dinâmica do uso da terra e analisar espacialmente os objetos de estudo ao longo do tempo. Valério Filho et al. (1997) utilizaram dados digitais do TM/Landsat e geoprocessamento para o monitoramento da dinâmica do uso agrícola e vegetação natural em microbacias hidrográficas. Esses autores concluíram que, mesmo não sendo possível um maior detalhamento das classes de uso e cobertura vegetal das terras, decorrente das limitações dos produtos de sensoriamento remoto orbital, as técnicas de sensoriamento remoto e geoprocessamento são ferramentas úteis para o monitoramento da dinâmica de uso e cobertura vegetal e a adequação de uso das terras ao nível de microbacias hidrográficas, por propiciarem maior frequência na atualização de dados, agilidade no processamento e serem economicamente viáveis.

Desse modo, neste trabalho, objetivou-se subsidiar o planejamento agrícola da sub-bacia hidrográfica do Ribeirão Vista Bela (MG) por meio da avaliação da aptidão agrícola das terras, do uso atual das terras, da identificação das áreas de preservação permanente e, finalmente, da verificação da inadequação entre o uso e a aptidão agrícola (cruzamento de informações).

\section{MATERIAL E MÉTODOS}

A sub-bacia hidrográfica de estudo é a do Ribeirão Vista Bela, inserida na Bacia do Alto Rio Grande, MG, no município de Andrelândia, com 175 ha de área de drenagem, entre as coordenadas UTM 559895 e 561563 m, 7597109 e 7598777 m, 23K, datum Córrego Alegre. Essa área é representativa da zona fisiográfica Campos das Vertentes e suas altitudes variam entre 960 e $1.080 \mathrm{~m}$, com clima Cwa (mesotérmico, com inverno seco e verão chuvoso e temperatura do mês mais quente superior a $22^{\circ} \mathrm{C}$ ), segundo Köppen (Antunes, 1986).

O mapa detalhado de solos, em escala 1:10.000, foi preparado com apoio de foto aérea pancromática vertical na escala 1:35.000. A caracterização dos perfis modais foi feita segundo Lemos et al. (2005) e a classificação taxonômica, segundo Embrapa (2006). As fases de relevo foram obtidas a partir de dados de declividade de um modelo digital de elevação do terreno com pixels de 30x30 $\mathrm{m}$ (Scolforo \& Carvalho, 2006), separando-se as seguintes classes de relevo: plano $(<3 \%)$, suave ondulado $(3 \%$ a $8 \%$ ), ondulado ( $8 \%$ a $20 \%$ ) e forte ondulado (20\% a $45 \%$ ). Maiores detalhes sobre o levantamento de solos e as classes de solo podem ser encontrados em Menezes (2007).

A avaliação da aptidão agrícola foi baseada na metodologia de Ramalho Filho \& Beek (1995), tendo como base o mapa pedológico e os resultados analíticos químicos e físicos representativos das unidades de mapeamento de solos. De posse desses dados, foi elaborada uma tabela onde para cada componente das unidades de mapeamento foram atribuídos graus de limitação relativos às cinco qualidades básicas da terra: deficiência de fertilidade, deficiência de água, excesso de água (ou deficiência de oxigênio), suscetibilidade à erosão e impedimentos à mecanização.

Levando-se em conta as práticas agrícolas que estão ao alcance dos agricultores da região, adotaram-se três níveis de manejo, os quais aparecem na simbologia da 
classificação, escrita em diferentes formas, de acordo com as classes de aptidão das terras em cada nível adotado, a saber: A - práticas agrícolas que refletem um baixo nível tecnológico, onde quase não há aplicação de capital para manejo, melhoramento e conservação das terras e lavouras, e uso de trabalho braçal ou alguma tração animal de implementos simples; B - práticas agrícolas que refletem um nível tecnológico médio, modesta aplicação de capital para manejo, melhoramento e conservação das terras e lavouras, práticas condicionadas à tração animal; e C práticas agrícolas que refletem um alto nível tecnológico onde há aplicação intensiva de capital para manejo, melhoramento e conservação das terras e lavouras, e há a presença de motomecanização em diferentes fases da operação agrícola

Para a elaboração do mapa de uso atual das terras, foi utilizada a classificação supervisionada da imagem do sensor ETM+ do satélite Landsat, datada de 7 de outubro de 2005. Foi utilizado o classificador estatístico máxima verossimilhança ("Maxver") do programa ENVI 8.3. Após esta classificação, as imagens foram corrigidas com a situação encontrada atualmente nas áreas estudadas, com o auxílio de fotos e observações de campo.

As áreas de preservação permanente (APPs) foram delimitadas com base na Lei Federal n ${ }^{\circ} 4.771$ de 1965, que instituiu o Código Florestal Brasileiro e na Resolução CONAMA n ${ }^{\circ} 4$ de 1985 e n 303 de 2002 . Desse modo, foram mapeadas as margens de rios, com uma faixa de 30 metros, pois os cursos d'água possuem menos de 10 metros de largura e as nascentes, num raio de 60 metros de largura. Foram consideradas apenas as áreas previstas em leis federais, não sendo usadas as normas e os procedimentos restritos do estado ou do município.

Os mapas de aptidão agrícola, uso atual e APPs, que consistem em planos de informação de entrada no SIG, foram unidos e sobrepostos com a ferramenta overlay/ union no programa ArcGis 9.2, o que permitiu determinar a taxa de adequação do uso das terras, mostrando sua posição geográfica e suas respectivas áreas com conflito de uso.

\section{RESULTADOS E DISCUSSÃO}

\section{Solos e aptidão agrícola das terras}

Com relação às classes de solos (Figura 1), verificase o predomínio de Latossolos (47\% da área) principalmente em relevo ondulado, sendo que os Latossolos VermelhoAmarelos apresentam maior expressão geográfica $(34,4 \%$ da área). Os Cambissolos Háplicos têm relevante expressão na área $(35,1 \%)$ e, juntamente com os Neossolos Litólicos (2,3\% da área), ocorrem nas porções mais movimentadas do terreno. Curi et al. (1994), estudando a mesma região e Araújo (2007), na bacia do Alto Rio Grande, encontraram Cambissolos e Latossolos em posições distintas na paisagem, em que os primeiros ocupam as partes mais movimentadas, ora no terço superior, ora no terço inferior, e os Latossolos ocupam as partes mais suavizadas. Os Neossolos Flúvicos (15,5\% da área), nas várzeas periodicamente inundáveis, completam o quadro pedológico da sub-bacia hidrográfica. Esses Neossolos Flúvicos ocorrem nas áreas mais planas, no entorno da rede de drenagem e são os solos de fertilidade natural mais elevada na paisagem, além de terem menores problemas relativos ao déficit hídrico, apesar de poderem apresentar certo risco de anoxia em períodos mais chuvosos.

O mapa das classes de aptidão agrícola das terras pode ser observado na Figura 2, e as classes de solos, fases de relevo, fatores limitantes e a especificação da aptidão agrícola das terras são apresentados na Tabela 1 . A Tabela 2 mostra a extensão e a expressão geográfica desses diferentes ambientes agrícolas.

De modo geral, os Cambissolos locais, com classes de aptidão $4 \mathrm{p}$ e $5 \mathrm{~S}$ apresentam diversas limitações ao cultivo agrícola, como a pequena espessura do sólum, baixa capacidade de armazenamento de água, baixa infiltração de água, presença de pedras e cascalhos e pobreza de nutrientes (Almeida \& Resende, 1985; Curi et al., 1994). Há ainda a possibilidade de ocorrer encrostamento, muito frequente nesses solos na Bacia do Alto Rio Grande, onde está inserida a sub-bacia em questão (Santos et al., 1998). Esses atributos aumentam a suscetibilidade à erosão, os impedimentos à mecanização e a deficiência de água para as plantas. Conforme podemos observar na Tabela 2, o relevo foi determinante para a aptidão agrícola desses ambientes, visto que os Cambissolos presentes em relevo forte ondulado possuem maiores limitações quanto à erosão quando comparados aos de relevo suave ondulado e ondulado. A mesma situação pode ser observada para o Latossolo Vermelho-Amarelo, presente também em relevo forte ondulado com aptidão 4P, aptidão inferior que os outros Latossolos em relevo mais suavizado, com aptidão 3(bc).

Excluindo-se as condições de relevo, os Latossolos, de forma geral, têm como principal limitação a baixa fertilidade natural, implicando em maior uso de capital no emprego de corretivos e fertilizantes. Embora tenham problemas de pobreza química, esses solos apresentam boas condições físicas, como permeabilidade e profundidade efetiva elevadas, proporcionando maior suprimento e armazenamento de água (Motta et al., 2001). 


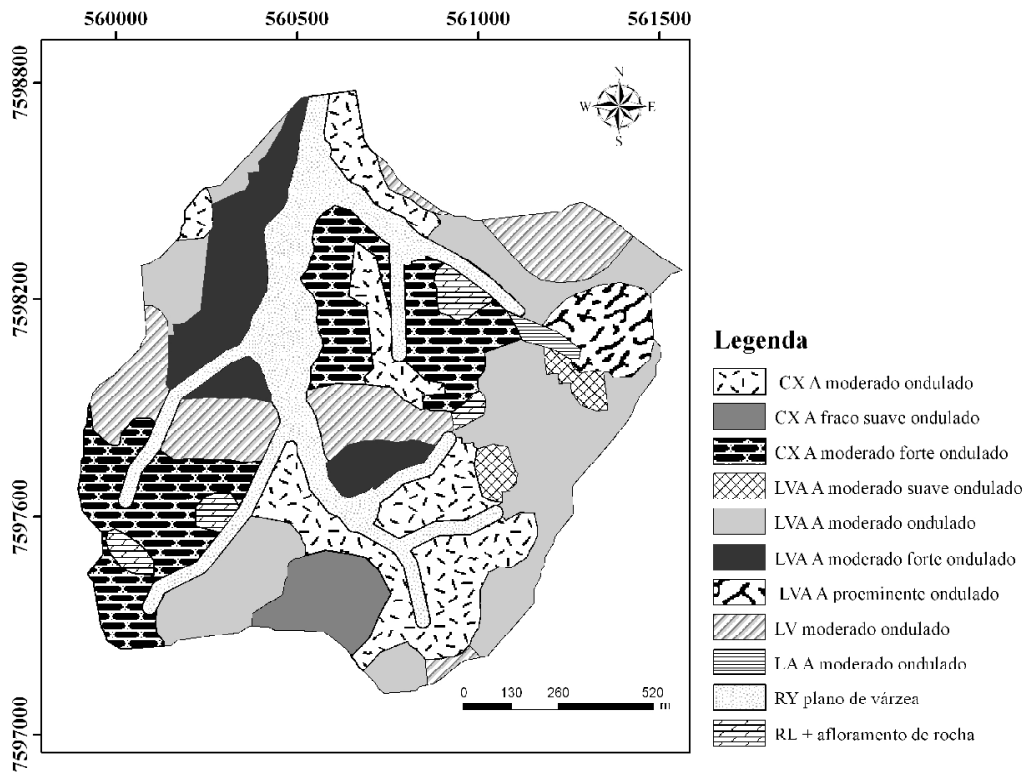

Figura 1 - Classes de solos e relevo da sub-bacia do Ribeirão Vista Bela.

CX: Cambissolo Háplico; LVA: Latossolo Vermelho-Amarelo; LV: Latossolo Vermelho; LA: Latossolo Amarelo; RY: Neossolo Flúvico; RL Neossolo Litólico.

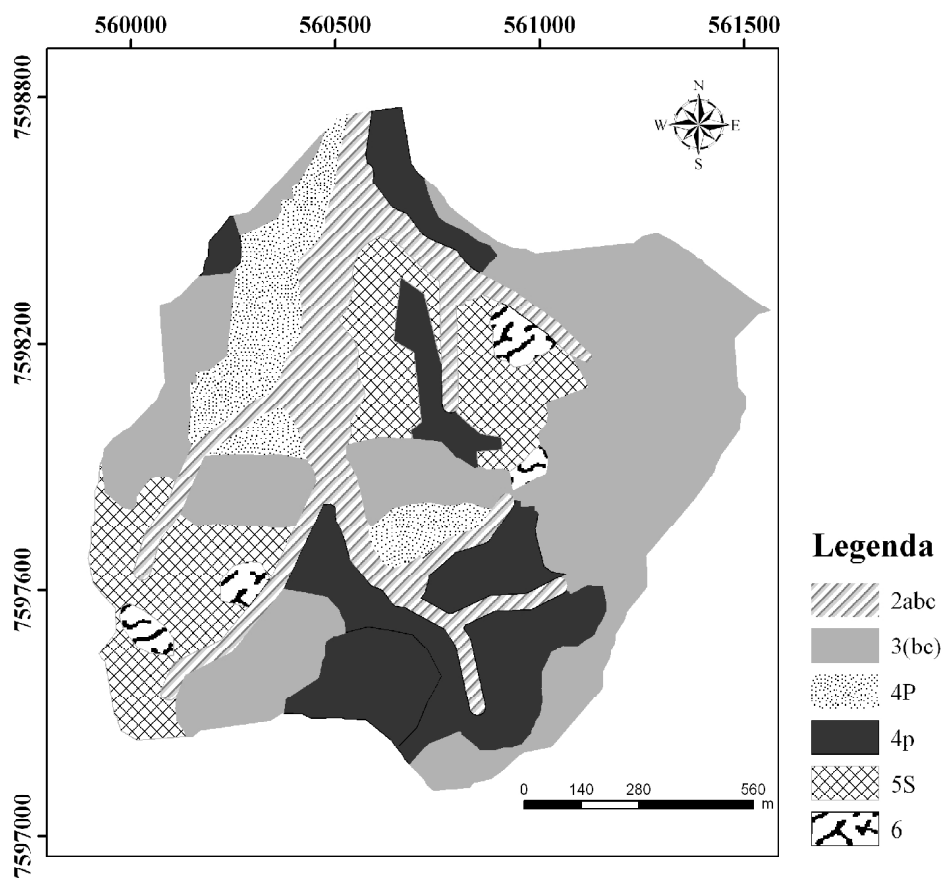

Figura 2 - Classes de aptidão agrícola das terras da sub-bacia do Ribeirão Vista Bela, onde: 2abc - aptidão regular para lavoura nos níveis de manejo A, B e C; 3(bc) - aptidão restrita para lavoura nos níveis de manejo B e C; 4P - aptidão boa para pastagem plantada; $4 \mathrm{p}$ - aptidão regular para pastagem plantada; $5 \mathrm{~S}$ - aptidão boa para silvicultura; e 6 - não apresenta aptidão agrícola. 
Tabela 1 - Aptidão agrícola das terras da sub-bacia do Ribeirão Vista Bela, classes de solos, fases de relevo e fatores mais restritivos à utilização das terras.

\begin{tabular}{|c|c|c|c|c|c|c|c|c|c|c|c|c|c|c|c|c|c|c|}
\hline \multirow{3}{*}{ Solos ${ }^{1}$} & \multirow{3}{*}{ Relevo $^{2}$} & \multicolumn{15}{|c|}{ Estimativa das limitações agrícolas das terras ${ }^{3}$} & \multirow{3}{*}{$\begin{array}{l}\text { Principais } \\
\text { fatores } \\
\text { limitantes }\end{array}$} & \multirow{3}{*}{$\begin{array}{l}\text { Aptidão } \\
\text { agrícola }^{4}\end{array}$} \\
\hline & & \multicolumn{3}{|c|}{$\Delta \mathrm{F}$} & \multicolumn{3}{|c|}{$\Delta \mathrm{A}$} & \multicolumn{3}{|c|}{$\Delta \mathrm{O}$} & \multicolumn{3}{|c|}{$\Delta \mathrm{E}$} & \multicolumn{3}{|c|}{$\Delta \mathrm{M}$} & & \\
\hline & & A & B & $\mathrm{C}$ & A & B & $\mathrm{C}$ & A & $\mathrm{B}$ & $\mathrm{C}$ & A & B & $\mathrm{C}$ & A & B & $\mathrm{C}$ & & \\
\hline $\mathrm{CX}$ & $\mathrm{SO}, \mathrm{O}$ & $\mathrm{N}$ & M1 & L2 & $\mathrm{L} / \mathrm{M}$ & $\mathrm{L} / \mathrm{M}$ & $\mathrm{L} / \mathrm{M}$ & $\mathrm{N}$ & $\mathrm{N}$ & $\mathrm{N}$ & $\mathrm{M} / \mathrm{F}$ & MF2 & MF3 & $\mathrm{F}$ & $\mathrm{F} 1$ & $\mathrm{~F} 2$ & $\mathrm{~F}, \mathrm{~A}, \mathrm{M}$ & $4 p$ \\
\hline CX & FO & $\mathrm{N}$ & M1 & L2 & $\mathrm{L} / \mathrm{M}$ & $\mathrm{L} / \mathrm{M}$ & $\mathrm{L} / \mathrm{M}$ & $\mathrm{N}$ & $\mathrm{N}$ & $\mathrm{N}$ & $\mathrm{F}$ & $\mathrm{F}$ & $\mathrm{L}$ & $\mathrm{F}$ & $\mathrm{F} 1$ & $\mathrm{~F} 2$ & $\begin{array}{c}\mathrm{F}, \mathrm{A}, \mathrm{E}, \\
\mathrm{M}\end{array}$ & $5 \mathrm{~S}$ \\
\hline LVA & $\mathrm{SO}, \mathrm{O}$ & $\mathrm{F}$ & M1 & L2 & $\mathrm{L} / \mathrm{M}$ & $\mathrm{L} / \mathrm{M}$ & $\mathrm{L} / \mathrm{M}$ & $\mathrm{N}$ & $\mathrm{N}$ & $\mathrm{N}$ & $\mathrm{M} / \mathrm{F} 1$ & $\mathrm{M} / \mathrm{F} 2$ & MF3 & $\mathrm{F}$ & $\mathrm{F} 1$ & $\mathrm{~F} 2$ & $\mathrm{~F}$ & $3(b c)$ \\
\hline LVA & FO & $\mathrm{F}$ & M1 & L2 & $\mathrm{L} / \mathrm{M}$ & $\mathrm{L} / \mathrm{M}$ & $\mathrm{L} / \mathrm{M}$ & $\mathrm{N}$ & $\mathrm{N}$ & $\mathrm{N}$ & $\mathrm{F}$ & $\mathrm{F}$ & $\mathrm{L}$ & $\mathrm{F}$ & $\mathrm{F} 1$ & $\mathrm{~F} 2$ & $\mathrm{~F}, \mathrm{E}$ & $4 \mathrm{P}$ \\
\hline LV & $\mathrm{O}$ & $\mathrm{F}$ & M1 & L2 & $\mathrm{L} / \mathrm{M}$ & $\mathrm{L} / \mathrm{M}$ & $\mathrm{L} / \mathrm{M}$ & $\mathrm{N}$ & $\mathrm{N}$ & $\mathrm{N}$ & $\mathrm{M} / \mathrm{F} 1$ & $\mathrm{M} / \mathrm{F} 2$ & MF3 & $\mathrm{F}$ & $\mathrm{F} 1$ & $\mathrm{~F} 2$ & $\mathrm{~F}$ & $3(b c)$ \\
\hline LA & $\mathrm{O}$ & $\mathrm{F}$ & M1 & L2 & $\mathrm{L} / \mathrm{M}$ & $\mathrm{L} / \mathrm{M}$ & $\mathrm{L} / \mathrm{M}$ & $\mathrm{N}$ & $\mathrm{N}$ & $\mathrm{N}$ & $\mathrm{M} / \mathrm{F} 1$ & $\mathrm{M} / \mathrm{F} 2$ & MF3 & $\mathrm{F}$ & $\mathrm{F} 1$ & $\mathrm{~F} 2$ & $\mathrm{~F}$ & $3(b c)$ \\
\hline RY & $\mathrm{P}$ & $\mathrm{L}$ & $\mathrm{N}$ & $\mathrm{N}$ & $\mathrm{N}$ & $\mathrm{N}$ & $\mathrm{N}$ & L/M1 & L/M1 & L/M1 & $\mathrm{N}$ & $\mathrm{N}$ & $\mathrm{N}$ & $\mathrm{L}$ & $\mathrm{L}$ & $\mathrm{L}$ & A & $2 a b c$ \\
\hline $\begin{array}{c}\text { RL+ } \\
\text { AR }\end{array}$ & FO & - & - & - & - & - & - & - & - & - & - & - & - & - & - & - & $\mathrm{F}, \mathrm{A}, \mathrm{E}, \mathrm{M}$ & 6 \\
\hline
\end{tabular}

(1) CX- Cambissolo Háplico; LVA - Latossolo Vermelho-Amarelo; LV - Latossolo Vermelho; LA - Latossolo Amarelo; RY Neossolo Flúvico; RL - Neossolo Litólico; AR - Afloramento de Rocha. (2) P - plano de várzea; SO - suave ondulado; O ondulado; FO - forte ondulado. (3) $\Delta \mathrm{F}$ - deficiência de fertilidade; $\Delta \mathrm{A}$ - deficiência de água; $\Delta \mathrm{O}$ - deficiência de oxigênio; $\Delta \mathrm{E}$ suscetibilidade à erosão; $\Delta \mathrm{M}$ - impedimentos à mecanização. (4) 2abc - aptidão regular para lavoura nos níveis de manejo $\mathrm{A}, \mathrm{B}$ e $\mathrm{C}$; 3(bc) - aptidão restrita para lavoura nos níveis de manejo B e C; 4P - aptidão boa para pastagem plantada; 4p - aptidão regular pastagem para plantada; 5S - aptidão boa para silvicultura; 6 - não apresenta aptidão agrícola. Graus de limitação: $\mathrm{N}$ - nulo; L ligeiro; M - moderado; F - forte; MF - muito forte; / intermediário.

Tabela 2 - Classes de solos, fases de relevo, aptidão agrícola das terras nos níveis de manejo A, B e C com suas respectivas extensões (ha) e distribuição percentual na sub-bacia do Ribeirão Vista Bela.

\begin{tabular}{ccccc}
\hline Solos $^{1}$ & Relevo & Aptidão agrícola $^{2}$ & Área (ha) & $\%$ \\
\hline CX & suave ondulado & $4 \mathrm{p}$ & 6,6 & 3,8 \\
CX & ondulado & $4 \mathrm{p}$ & 26,7 & 15,3 \\
CX & forte ondulado & $5 \mathrm{~S}$ & 28,0 & 16,0 \\
LVA & suave ondulado & $3(\mathrm{bc})$ & 2,8 & 1,6 \\
LVA & ondulado & $3(\mathrm{bc})$ & 42,6 & 24,3 \\
LVA & forte ondulado & $4 \mathrm{P}$ & 14,8 & 8,5 \\
LV & ondulado & $3(\mathrm{bc})$ & 21,3 & 12,2 \\
LA & ondulado & $3(\mathrm{bc})$ & 1,0 & 0,6 \\
RY & plano de várzea & $2 \mathrm{abc}$ & 27,2 & 15,5 \\
RL + AR & forte ondulado & 6,0 & 2,3 \\
Total & & & 175,0 & 100,0 \\
\hline
\end{tabular}

(1) CX- Cambissolo Háplico; LVA - Latossolo Vermelho-Amarelo; LV - Latossolo Vermelho; LA - Latossolo Amarelo; RY Neossolo Flúvico; RL - Neossolo Litólico; AR - Afloramento de Rocha. (2) 2abc - aptidão regular para lavoura nos níveis de manejo A, B e C; 3(bc) - aptidão restrita para lavoura nos níveis de manejo B e C; 4P - aptidão boa para pastagem plantada; 4p aptidão regular para pastagem plantada; 5S - aptidão boa para silvicultura; 6 - não apresenta aptidão agrícola.

As áreas com melhor aptidão são representadas pelos Neossolos Flúvicos. Apresentam fertilidade natural relativamente mais elevada e estão presentes nas áreas mais planas (de várzea) desta sub-bacia. Sua posição na paisagem reduz os problemas associados à falta de água. Por outro lado, o risco de inundação (falta de oxigênio) 
eventual em anos mais chuvosos é o fator mais limitante ao uso agrícola desses ambientes de solos.

Já os Neossolos Litólicos foram considerados inaptos para a agricultura, em razão da escassez de água (pequena profundidade efetiva), ao relevo forte ondulado e à maior exposição aos efeitos da enxurrada (menor capacidade de infiltração de água), além de pedregosidade e rochosidade que dificultam o uso de implementos agrícolas. Outro problema é que a água, ao atingir o material de origem, tem seu fluxo diminuído drasticamente, expondo esses solos aos efeitos do escoamento subsuperficial. Esse problema é mais sério em áreas mais acidentadas desprovidas de vegetação, as quais são mais indicadas para uso como preservação ambiental (Oliveira et al., 1994).

\section{Uso atual das terras}

As classes de uso atual das terras para a sub-bacia do Ribeirão Vista Bela estão apresentadas na Tabela 3.

A identificação das pastagens degradadas foi possível com o uso das imagens de satélite aliadas a observações de campo, as quais permitiram discriminar feições correspondentes às áreas de solos mais expostos, com pastagens que proporcionam menor cobertura ao solo. Desse modo, foi possível constatar a presença de áreas já afetadas pelo manejo inadequado, como é o caso das pastagens degradadas em extensão considerável na sub-bacia. Merece destaque, também, o fato da vegetação nativa ter sido, em grande parte, convertida para pastagem.

\section{Taxa de adequação do uso das terras}

Ao cruzar os mapas de aptidão agrícola e de uso atual das terras, foi possível determinar a taxa de adequação do uso das mesmas (Tabela 4).

Ocorre o predomínio de terras com usos menos intensivos que o seu potencial agrícola, ou seja, 139,4 ha $(79,7 \%)$ podem ser utilizados de maneira mais intensiva em relação ao seu uso atual, de acordo com o sistema de avaliação da aptidão agrícola das terras. Isso ocorre, principalmente, em razão da grande extensão da pastagem nativa, mesmo que grande parte da sub-bacia hidrográfica tenha aptidão para lavoura.

Do ponto de vista da sustentabilidade ambiental, não há problemas se as terras estão sendo utilizadas de maneira menos intensiva em relação a sua aptidão agrícola. Em tese, pode-se esperar um maior retorno econômico se estas terras estivessem sendo utilizadas, por exemplo, com lavoura, desde que tenham aptidão para tal, nesse caso, deve-se considerar também o poder aquisitivo do produtor da região, o que é determinante para os diferentes níveis de manejo adotados para as terras.

Tabela 3 - Classes de uso e suas respectivas extensões (ha) e descrições.

\begin{tabular}{lcl}
\hline \multicolumn{1}{c}{ Classes de uso } & Área (ha) & \multicolumn{1}{c}{ Descrição } \\
\hline Mata ciliar & 31,7 & $\begin{array}{l}\text { Ocorre principalmente no entorno da rede de drenagem e em } \\
\text { muitos locais vem sendo substituída por pastagens }\end{array}$ \\
Pastagem nativa & 74,0 & $\begin{array}{l}\text { Composta principalmente pela espécie Echinolaena inflexa } \\
\text { Pastagem nativa degradada }\end{array}$ \\
Pastagem plantada & 35,2 & (capim flechinha) \\
Pastagem plantada degradada & 2,7 & Composta principalmente pelas espécies Brachiaria decumbens, \\
\hline
\end{tabular}

Tabela 4 - Extensões do uso atual (ha) em relação à aptidão agrícola das terras da sub-bacia do Ribeirão Vista Bela.

\begin{tabular}{|c|c|c|c|c|c|c|}
\hline \multirow[t]{2}{*}{ Uso atual } & \multicolumn{6}{|c|}{ Subgrupo de aptidão } \\
\hline & $2 a b c$ & $3(\mathrm{bc})$ & $4 \mathrm{P}$ & $4 p$ & $5 \mathrm{~S}$ & 6 \\
\hline Mata ciliar & $9,2 \S$ & $11,7 \S$ & $2,1 \S$ & $2,8 \S$ & $4,8 \S$ & $1,1 \uparrow$ \\
\hline Pastagem nativa & $8,6 \S$ & $30,0 \S$ & $9,4 \S$ & $15,1 \S$ & 9,90 & 1,00 \\
\hline Pastagem nativa degradada & $3,5 \S$ & $9,6 \S$ & - & $10,6 \S$ & 9,50 & 2,00 \\
\hline Pastagem plantada & $5,6 \S$ & $15,7 \S$ & $3,4 \stackrel{\dagger}{+}$ & $3,7 \dagger$ & 3,10 & \\
\hline Pastagem plantada degradada & $0,1 \S$ & $0,6 \S$ & - & $1,2 \dagger$ & $0,8 \mathrm{a}$ & \\
\hline
\end{tabular}

$\S$ - terras com usos menos intensivos que o da classe de aptidão - uso adequado; $\alpha$ - terras com usos mais intensivos que o d $\varepsilon$ classe de aptidão - uso inad equado: $\uparrow$ - terras com uso s coincidentes com as exigências da classe de aptidão - uso adequado. 
Deve-se também atentar para a baixa qualidade das pastagens, onde parcela significativa encontra-se degradada, refletindo em perda de produtividade, o que é uma constante na zona fisiográfica Campos das Vertentes onde se insere a sub-bacia em questão. Segundo Albernaz \& Lima (2007), a degradação de pastagens tem consequências abrangentes, podendo ocasionar impactos negativos no solo e recursos hídricos, podendo afetar mananciais devido a efeitos da erosão. Motta et al. (2001) e Gomes et al. (2007), trabalhando em uma microbacia hidrográfica no município de Nazareno (MG), relatam que o uso de pastagens de má qualidade está proporcionando cobertura deficiente ao terreno, causando perdas de solo e contribuindo para o assoreamento do reservatório da hidrelétrica de Itutinga/Camargos, a jusante, com consequente redução de sua vida útil. Giarola (1994) e Araújo (2007), em estudos na Bacia do Alto Rio Grande e em áreas sob influência do reservatório de Itutinga/Camargos, respectivamente, em Minas Gerais, corroborando com os autores supracitados, encontraram como uso mais expressivo as pastagens de baixa qualidade, o que ajuda a explicar os graves problemas que se refletem na socioeconomia regional.

Áreas com usos mais intensivos que o da classe de aptidão representam 26,3 ha (15\%) do total, decorrente do avanço da pastagem extensiva sobre áreas inaptas para o pastoreio, representando risco de degradação ambiental. Apenas 9,4 ha $(5,3 \%)$ das terras da sub-bacia apresentam uso coincidente com as exigências da classe de aptidão, representadas, principalmente, por pastagens plantadas e por fragmentos de matas ciliares nas áreas inaptas para a agricultura.

Uso atual e aptidão agrícola nas áreas de preservação permanente na sub-bacia do Ribeirão Vista Bela

Com base nos parâmetros regidos por lei, foi gerado o mapa da sub-bacia do Ribeirão Vista Bela, com suas respectivas APPs, conforme se pode observar na Figura 3.

O emprego do Sistema de Avaliação da Aptidão Agrícola das Terras não abrange a legislação ambiental, ou seja, independentemente da aptidão da terra ser boa, regular, restrita ou inapta, ela deve ser preservada, se está em área de preservação permanente. Essas áreas não são consideradas para alteração de uso da terra e devem estar cobertas por vegetação nativa. Na Tabela 5, são mostrados o uso atual e a aptidão agrícola somente para as áreas consideradas como APPs, que representam 19,4\% do total da sub-bacia. Áreas ocupadas com mata ciliar foram consideradas como de uso adequado e as áreas com pastagens, foram consideradas como inadequadas.

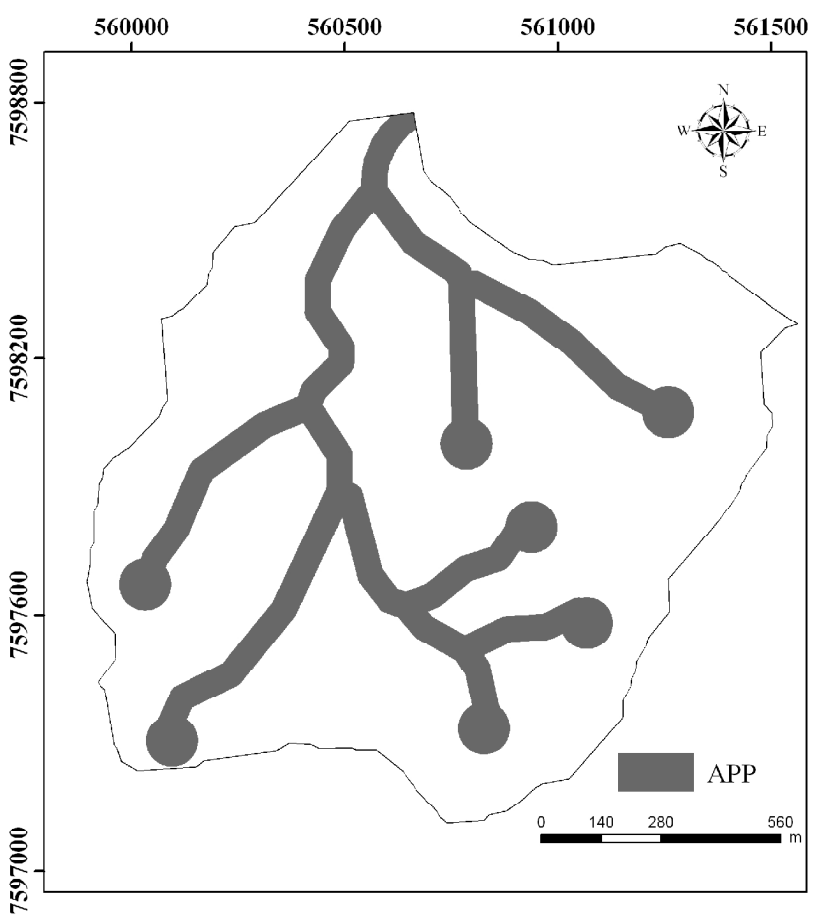

Figura 3 - Áreas de preservação permanente (APPs) na sub-bacia do Ribeirão Vista Bela. 
Tabela 5 - Uso atual, adequação do uso atual e aptidão agrícola das APPs na sub-bacia do Ribeirão Vista Bela.

\begin{tabular}{|c|c|c|c|}
\hline Uso atual & Adequação $^{1}$ & Aptidão agrícola & Área (ha) \\
\hline Mata ciliar & A & $2 a b c$ & 8,0 \\
\hline Mata ciliar & A & $3(\mathrm{bc})$ & 3,4 \\
\hline Mata ciliar & A & $4 \mathrm{p}$ & 0,6 \\
\hline Mata ciliar & A & $5 \mathrm{~S}$ & 2,0 \\
\hline Pastagem nativa & NA & $2 a b c$ & 4,6 \\
\hline Pastagem nativa & NA & $3(\mathrm{bc})$ & 0,8 \\
\hline Pastagem nativa & NA & $4 \mathrm{p}$ & 2,5 \\
\hline Pastagem degradada & NA & $2 a b c$ & 3,4 \\
\hline Pastagem degradada & NA & $4 p$ & 1,0 \\
\hline Pastagem degradada & NA & $5 \mathrm{~S}$ & 1,2 \\
\hline Pastagem plantada & NA & $2 a b c$ & 5,5 \\
\hline Pastagem plantada & NA & $4 p$ & 1,0 \\
\hline Total & & & 34,0 \\
\hline
\end{tabular}

${ }^{1} \mathrm{~A}$ - situação adequada; NA - situação não adequada.

Pode-se observar a ocorrência de uso não adequado com pastagens em 20 ha $(58,8 \%)$ da área destinada às APPs. Essas áreas deveriam, em sua totalidade, estar cobertas por vegetação nativa, sendo vedada a sua utilização e, consequentemente, a remoção de suas coberturas vegetais originais. A importância da preservação ou da restauração da mata ciliar nessas áreas fundamenta-se no amplo espectro de benefícios que essa vegetação traz ao ecossistema, exercendo função protetora sobre os recursos naturais bióticos e abióticos (Durigan \& Silveira, 1999) e desempenhando uma série de processos importantes que permitem manter a integridade e a estabilidade da bacia hidrográfica (Lima \& Zakia, 2000).

É importante ressaltar o fato de que localmente é nas áreas destinadas às APPs que se encontram, em grande parte, as terras com aptidão agrícola mais elevada (2abc), áreas mais planas no entorno da rede de drenagem, onde ocorrem os Neossolos Flúvicos. Nessas áreas, o processo de desmatamento seguido da implantação de pastagem de baixa qualidade, com consequente degradação, é antigo. Esse uso mais intensivo é decorrente do fato de estas áreas estarem situadas em áreas relativamente mais férteis e úmidas. Entretanto, elas não estão livres de processos de degradação. O manejo inadequado das pastagens nativas da região é uma constante, com consequente redução da fertilidade do solo em função da exportação de nutrientes e problemas com encrostamento e compactação do solo, esta causada pelo pisoteio do gado (Martins, 2001), além do risco eminente de contaminação do ecossistema pela proximidade dos cursos d'água.

\section{CONCLUSÕES}

O levantamento pedológico forneceu uma base segura e real para que, com o auxílio de ferramentas de geoprocessamento, os mapas resultantes tivessem melhor qualidade e representassem com acurácia os diferentes ambientes naturais na paisagem da sub-bacia hidrográfica.

Para as terras da sub-bacia estudada que podem ser utilizadas com agricultura, os principais fatores limitantes são a declividade acentuada e a baixa fertilidade natural, exigindo emprego de capital e de técnicas para que alcancem seu máximo potencial produtivo de forma sustentável.

As terras inaptas para a agricultura situam-se nas áreas de solos com pequena profundidade, relevo acidentado e muita pedregosidade e rochosidade.

Predomina o uso das terras com pastagem nativa (degradada ou não), que é, em boa parte, menos intensivo que o das classes de aptidão e não acarreta grandes riscos na conservação do solo e da água.

As áreas de preservação permanente têm diferenciados usos agrícolas, não sendo verificada a manutenção da vegetação nativa, em grande parte da área, conforme determina a lei. Nessas áreas, localizam-se as terras com melhor aptidão agrícola.

\section{AGRADECIMENTOS}

Agradecemos ao $\mathrm{CNPq}$ pelos recursos disponibilizados e a CEMIG pelo financiamento do projeto de pesquisa e desenvolvimento. 


\section{REFERÊNCIAS BIBLIOGRÁFICAS}

ALBERNAZ, W. M.; LIMA, J. M. de. Caracterização da cobertura vegetal de pastagens em duas sub-bacias hidrográficas da região da Lavras, MG. Ciência e Agrotecnologia, Lavras, v.31, n.2, p.290-297, mar./abr., 2007.

ALMEIDA, J.R.; RESENDE, M. Considerações sobre o manejo de solos rasos desenvolvidos de rochas pelíticas no Estado de Minas Gerais. Informe Agropecuário, Belo Horizonte, v.11, n.128, p.19-26, ago. 1985.

ANTUNES, F.Z. Caracterização climática do Estado de Minas Gerais. Informe Agropecuário, Belo Horizonte, v.12, n.138, p.9-13, jun. 1986.

ARAÚJO, A.R. Solos da bacia do Alto Rio Grande (MG): base para estudos hidrológicos e aptidão agrícola. 2007. 332p. Tese (Doutorado em Solos e Nutrição de Plantas)Universidade Federal de Lavras, Lavras, 2007.

CURI, N.; CHAGAS, C.S.; GIAROLA, N.F.B. Distinção de ambientes agrícolas e relações solo-pastagens nos Campos da Mantiqueira (MG). In: EVANGELISTA, A.R.; CARVALHO, M.M.; CURI, N. (Eds.). Desenvolvimento de pastagens na zona fisiográfica Campos das Vertentes, MG: reunião de trabalho sobre pastagens nativas e desenvolvimento de pastagens para gado de leite nos Campos das Vertentes. Lavras: ESAL/Embrapa, 1994. p.21-43.

DURIGAN, G.; SILVEIRA, E.R. Recomposição da mata ciliar em domínio de cerrado, Assis, SP. Scientia Forestalis, Piracicaba, v.56, p.135-144, dez. 1999.

\section{EMPRESA BRASILEIRA DE PESQUISA}

AGROPECUÁRIA. Centro Nacional de Pesquisa de Solos. Sistema brasileiro de classificação de solos. 2.ed. Rio de Janeiro: CNPS, 2006. 306p.

FORMAGGIO, A.R.;ALVES, D.S.; EPIPHANIO, J.C.N. Sistema de informações geográficas na obtenção de aptidão agrícola e de taxas de adequação de uso das terras. Revista Brasileira de Ciência do Solo, Viçosa, v.16, n.2, p.249-256, 1992.

GIAROLA, F.B. Levantamento pedológico, perdas de solo e aptidão agrícola das terras na região sob influência do reservatório da hidrelétrica de Ututinga/Camargos (MG). 1994. 235p. Dissertação (Mestrado em Solos e
Nutrição de Plantas)-Escola Superior de Agricultura de Lavras, Lavras, 1994.

GOMES, N.M.; FARIA, M.A.; SILVA, A.M.; MELLO, C.R.; VIOLA, M.R. Variabilidade espacial de atributos físicos do solo associada ao uso e ocupação da paisagem. Revista Brasileira de Engenharia Agrícola e Ambiental, Campina Grande, v.11, n.4, p.427-435, 2007.

LEMOS, R.C.; SANTOS, R.D.; SANTOS, H.G.; KER, J.C.; ANJOS, L.H.C. Manual de descrição e coleta de solo no campo. 5.ed. Viçosa, MG: SBCS, 2005. 92p.

LIMA, W.P.; ZAKIA, M.J.B. Hidrologia em matas ciliares. In: RODRIGUES, R.R.; LEITÃO FILHO, H. (Eds.). Matas ciliares: conservação e recuperação. São Paulo: EDUSP/Fapesp, 2000. p.33-44.

MARTINS, S.V. Recuperação de matas ciliares. Viçosa, MG: Aprenda Fácil, 2001. 146p.

MENEZES, M.D. Levantamento de solos em sub-bacia hidrográfica como apoio para avaliação do uso da terra e da potencialidade de recarga de aquíf́eros. 2007. 107p. Dissertação (Mestrado em Ciência do Solo)Universidade Federal de Lavras, Lavras, 2007.

MOTTA, P.E.F.; CURI, N.; SILVA, M.L.N.; MARQUES, J.J.G.S.M.; PRADO, N.J.S.; FONSECA, E.M.B. Levantamento pedológico detalhado, erosão dos solos, uso atual e aptidão agrícola das terras de microbacia piloto na região sob influência do reservatório da hidrelétrica de Itutinga/Camargos-MG. Belo Horizonte: CEMIG, 2001. 51p.

OLIVEIRA, G.C.; FERREIRA, M.M.; CURI, N. Caracterização físico-hídrica de Cambissolos da microrregião Campos da Mantiqueira (MG). Ciência e Prática, Lavras, v.18, n.4, p.341-348, out./dez. 1994.

PEDRON, F.A.; POELKING, E.L.; DALMOLIN, R.S.D.; AZEVEDO, A.C.; KLAMT, E. A aptidão de uso da terra como base para o planejamento da utilização dos recursos naturais no município de São João do Polinese - RS. Ciência Rural, Santa Maria, v.36, n.1, p.105-112, jan./fev. 2006.

RAMALHO FILHO, A.; BEEK, K.J. Sistema de avaliação da aptidão agrícola das terras. 3.ed. rev. Rio de Janeiro: Embrapa/CNPS, 1995. 65p. 
RESENDE, J.C.; PEREIRA, J.R. Região Campos das Vertentes: aspectos geográficos, socioeconômicos e potencialidade para produção de leite. In:

EVANGELISTA, A.R.; CARVALHO, M.M.; CURI, N. (Eds.). Desenvolvimento de pastagens na zona

fisiográfica Campos das Vertentes, MG: reunião de trabalho sobre pastagens nativas e

desenvolvimento de pastagens para gado de leite nos Campos das Vertentes. Lavras: ESAL/Embrapa, 1994. p.1-20.

ROY, P.S.; TOMAR, S. Landscape cover dynamics pattern in Meghalaya. Remote Sensing, Basingstoke, v.22, n.18, p.3813-3825, 1995.

SANTOS, D.; CURI, N.; FERREIRA, M.M.; EVANGELISTA, A.R.; CRUZ, A.B.; TEIXEIRA, W.G. Perdas de solo e produtividade de pastagens nativas melhoradas sob diferentes práticas de manejo. Pesquisa
Agropecuária Brasileira, Brasília, v.33, n.2, p.183-189, fev. 1998.

SCOLFORO, J.R.S.; CARVALHO, L.M.T. Mapeamento e inventário da flora nativa e do reflorestamento de Minas Gerais. Lavras: UFLA, 2006. 28p.

SILVA, F. M. da; SOUZA, Z. M. de; FIGUEIREDO, C. A. P. de; VIEIRA, L. H. de S.; OLIVEIRA, E. de.

Variabilidade espacial de atributos químicos e produtividade da cultura do café em duas safras agrícolas. Ciência e Agrotecnologia, Lavras, v.32, n.1, p.231-241, jan./fev., 2008.

VALÉRIO FILHO, M.; DONZELI, P.L.; PINTO, S.A.F. Monitoramento da dinâmica do uso agrícola e vegetação natural em microbacias hidrográficas através de técnicas de sensoriamento remoto e geoprocessamento. In: CONGRESSO BRASILEIRO DE CIÊNCIA DO SOLO, 26., 1997, Rio de Janeiro. Anais... Rio de Janeiro: SBCS, 1997. CD-ROM. 